1 PhD student, Department of Restorative Dentistry, Piracicaba Dental School, University of Campinas - UNICAMP, Piracicaba, SP, Brazil

2 Assistant professor, Department of Clinical Dentistry, Faculdade de Odontologia, Universidade Federal do Rio de Janeiro - UFRJ, Rio de Janeiro, Brazil.

${ }^{3}$ Full Professor, Department of Statistical Mathematics, Escola Superior de Agronomia Luiz de Queiroz, University of Sao Paulo USP, Piracicaba, SP Brazil

${ }^{4}$ Full professor - Department of Restorative Dentistry, Piracicaba Dental School, University of Campinas - UNICAMP, Piracicaba, SP, Brazi

Corresponding author: Suelem Chasse Barreto University of Campinas, Piracicaba Dental School, Department of Restorative Dentistry, Piracicaba SP - Brazil

Avenida Limeira, 901, Areião. Zip Code 13414-903 - P.O. BOX 52 Phone: 55 -19-8841 5291 E-mail: suchasse@yahoo.com.br ORCID: 0000-0001-8085-1275

Received: November 23, 2018 Accepted: April 16, 2019

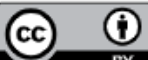

\section{Effects of primer excess on marginal adaptation, nanoleakage and bond strength of adhesive systems after aging}

\author{
Suelem Chasse Barreto', Isabel Ferreira Barbosa', \\ Gisele Damiana da Silveira Pereira ${ }^{2}$, Carlos Tadeu dos \\ Santos Dias ${ }^{3}$, Luís Alexandre Maffei Sartini Paulillo ${ }^{4}$
}

There is no consensus about the amount of primer inserted into the cavity. Aim: This study aimed to evaluate the effects of the amount of primer used on dentin microtensile bond strength ( $\mu \mathrm{TBs})$, nanoleakage and marginal sealing, following thermomechanical aging. Methods: 48 human third molars were selected and a box-shaped class I cavity was constructed to maintain enamel margins. Teeth were randomly assigned to 6 experimental groups $(n=8)$. For the bonding protocols of the restorative procedure, two adhesive systems were used: three-step etch-and-rinse and two-step self-etch. Epoxy resin replicas of the occlusal surface were made, and the specimens were submitted to thermomechanical aging. Newer replicas were obtained after thermomechanical aging, and marginal adaptation was observed using SEM. To obtain sections $(0.7 \times 0.7 \mathrm{~mm})$ for testing at a tension of $0.5 \mathrm{~mm} / \mathrm{min}$, teeth were serially sectioned in the buccallingual direction, parallel to the occlusal surface. Failure mode was then obtained. For nanoleakage evaluation, one section of each tooth was immersed in $\mathrm{AgNO}_{3}$ and evaluated using SEM. The $\mu \mathrm{TBs}$ data were submitted to a two-way ANOVA and Tukey's test $(\alpha=0.05)$ Results: One drop of primer promoted higher $\mu$ TBs than two or three drops. Besides, the three-step etch-and-rinse promoted greater $\mu$ TBs (19.78) than the two-step self-etch adhesive (12.23). The increase in the amount of primer was directly proportional to the increase of infiltration. All groups exhibited more gaps after thermomechanical aging. Conclusion: Using an excess of primer is not recommended because it reduces the $\mu \mathrm{TBs}$ and forms an unsatisfactory hybrid layer.

Keywords: Tensile strength. Dentin-bonding agents. Dental leakage. 


\section{Introduction}

The primer serves to facilitate penetration of the hydrophilic monomers forming the hybrid layer. It should not be applied in excess, however, because it is primarily composed of hydrophilic monomers such as 2-hydroxyethyl methacrylate (HEMA). These monomers form few crosslinks and tend to absorb water ${ }^{1}$ such that in excess, they solubilize the primer and reduce the monomer degree of polymerization, thus plasticizing the polymer matrix ${ }^{2-4}$.

The amount of primer inserted into the cavity during the installation of an adhesive system after etching is not standardized. In addition, the "moist and shiny surface" recommended by the manufacturer, is not only subjective but also varies widely between the different instructions of adhesives systems ${ }^{5}$.

The low degree of monomer conversion, the excess water and the consequent decrease of mechanical properties of adhesive systems are the main causes of the decline in hybrid layer quality, durability, and the failure of adhesive restorations $s^{3,5-8}$.

The majority of in vitro studies test materials under different conditions of the oral environment. Research that seeks to simulate these conditions, for example thermomechanical aging, produce results with greater applications and clinical significance $e^{9,10}$.

The objective of this study was to investigate the effect of the amount of primer used to hybridize substrate, on the bond strength of the buccal wall and the restorative material, marginal adaptation, and nanoleakage in class I type restorations following thermomechanical aging. The tested hypotheses were: (1) the adhesive system has no effect on microtensile bond strength; (2) the amount of primer applied to the substrate affects microtensile bond strength; (3) the amount of primer affects the quality of the hybrid layer (nanoleakage); and (4) Excess primer on the walls of the cavity increases the formation of marginal gaps after thermomechanical aging.

\section{MATERIALS AND METHODS}

Forty-eight freshly extracted human third molars were collected with informed consent of the patients and approval by the Institutional ethical review board (118/2013). To disinfect, teeth were incubated in a buffered $0.1 \%$ thymol solution at $37^{\circ} \mathrm{C}$ for 24 hours. Following cleaning, teeth were stored in distilled water until cavity preparation. The roots were embedded in polystyrene resin, and the occlusal surfaces were sanded under running water in a polishing machine (Politriz, AROTEC, São Paulo, SP, Brazil) with 400-, 800-, 1200-grit sandpaper (3M ESPE 411Q, Sumaré, SP, Brazil) to expose a flat enamel surface area without dentin exposure. Class I cavities were prepared using \#56 carbide burs (KG Sorensen, Barueri, SP, Brazil) at high-speed, under air/water cooling in a custom made apparatus that allowed the standardization of the cavity dimensions to $5 \mathrm{~mm}$ mesial-distal, $4 \mathrm{~mm}$ buccal-lingual, and a $3 \mathrm{~mm}$ depth, maintaining the cavity margins on the enamel substrate. The bur was replaced after five-cavity preparations.

For the restorative procedure, two adhesive systems were used for the bonding protocols: three-step etch-and-rinse (SBMP; 3M ESPE, Sumaré, SP, Brazil), and two-step self-etching primer (CF; Kuraray Medical Inc., Tokyo, JHS, Japan) and one composite 
resin Charisma (Heraeus kulzer, Hanau, Germany). The composition, manufacturer, and batch number of the materials used in this study are presented in Table 1. After cavity preparation, the teeth were randomly assigned to 6 experimental groups $(n=8)$ according to factors: \# of drops of primer (1, 2 or 3 ) and adhesive system (total-etch versus self-etching primer). The restorative procedure is described in table 2.

The restorations were finished with 600, 1200 and 2000 grit Silicon Carbide (SiC) paper under running water and then polished with 3, 1, and $0.5 \mu \mathrm{m}$ diamond paste (Arotec Ind. Com., São Paulo, SP, Brazil) using a polishing machine (AROTEC, São

Table 1. Materials used: Composition, manufacturer and batch number of adhesive systems and composite resin.

\begin{tabular}{lccc}
\hline Materials & Composition & Batch number & Manufacturer \\
\hline Ultradent etchant & $35 \%$ phosphoric acid & B962F & $\begin{array}{c}\text { Ultradent, South Jordan, } \\
\text { UT, USA. }\end{array}$ \\
\hline $\begin{array}{l}\text { Adper Scotch bond } \\
\text { multipurpose }\end{array}$ & $\begin{array}{c}\text { Primer: HEMA, polyalkenoic } \\
\text { acid copolymer, water }\end{array}$ & N468525 & $\begin{array}{c}\text { 3M ESPE, Sumaré, SP, } \\
\text { Brazil }\end{array}$ \\
\hline Bond: HEMA, bis- GMA, amines & 465871 & \\
\hline Clearfil SE Bond & $\begin{array}{c}\text { Primer: 10-MDP, HEMA, } \\
\text { Dimetacrilate hidrofilic, } \\
\text { Camphoroquinone, Terciary } \\
\text { amine, Water }\end{array}$ & 01147A & $\begin{array}{c}\text { Kuraray Medical INC. } \\
\text { Okayama, Japan }\end{array}$ \\
\hline
\end{tabular}

Bond: HEMA, 10- MDP, Bis-

GMA, Dimetacrilate Hidrofílic,

Terciary amine, Sílic Coloidal

silanizaded, Camphoroquinone.

01414A

BIS-GMA, barium fluoride glass

aluminum $(0.02-2 \mu \mathrm{m})$, silicon dioxide highly dispersed $(0.02$

$0.07 \mu \mathrm{m})$, camphoroquinone.

Heraeus kulzer, Hanau, Germany

HEMA: 2- hydroxyethylmethacrilate; Bis-GMA: bisphenol glycidyl methacrylate; 10 MDP: 10-Metacriloiloxi -decil dihidrogenado phosphatase.

Table 2. Experimental groups.

\begin{tabular}{|c|c|}
\hline Group & Restorative Procedures \\
\hline 1SBMP & $\begin{array}{l}\text { Total etching with } 35 \% \text { phosphoric acid (Ultradent Etchant, Ultradent, South Jordan, UT, USA) } \\
\text { for } 30 \mathrm{~s} \text { in enamel and } 15 \mathrm{~s} \text { in dentin. The surface was washed thoroughly with water for } 30 \\
\mathrm{~s} \text { and dried with wet cotton pellet. One drop of primer ( } 5 \mu \mathrm{L}) \text { was applied to the surface of the } \\
\text { entire preparation for } 15 \mathrm{~s} \text {, and, after solvent evaporation, one drop of adhesive was applied and } \\
\text { light-cured for } 15 \mathrm{~s} \text { with Radii-cal (RD) (SDI Limited, Victoria, Australia), at } 1200 \mathrm{~mW} / \mathrm{cm}^{2} \text {. For } \\
\text { the restoration, the cavity received } 8 \text { increments ( } 7 \text { oblique followed by } 1 \text { flat) with a microhybrid } \\
\text { composite (Charisma), and each increment was light cured for } 25 \mathrm{~s} \text {. }\end{array}$ \\
\hline 2SBMP & Same procedure as 1 SBMP, except with 2 drops of primer. \\
\hline 3SBMP & Same procedure as 1SBMP, except with 3 drops of primer. \\
\hline $1 \mathrm{CF}$ & $\begin{array}{l}\text { Acid-etching with } 35 \% \text { phosphoric acid of cavosurface enamel for } 30 \mathrm{~s} \text {. The surface was washed } \\
\text { thoroughly with water for } 30 \mathrm{~s} \text { and air-dried. One drop of primer }(5 \mu \mathrm{L}) \text { was applied to the cavity, } \\
\text { and, after solvent evaporation, one drop of adhesive was applied and light-cured for } 15 \mathrm{~s} \text { with } \\
\text { RD. For the restoration, the cavity received } 8 \text { increments ( } 7 \text { oblique followed by } 1 \text { flat) with a } \\
\text { microhybrid composite (Charisma), and each increment was light cured for } 25 \mathrm{~s} \text {. }\end{array}$ \\
\hline $2 \mathrm{CF}$ & Same procedure as $1 \mathrm{CF}$, except with 2 drops of primer. \\
\hline $3 \mathrm{CF}$ & Same procedure as $1 \mathrm{CF}$, except with 3 drops of primer. \\
\hline
\end{tabular}

SBMP = Scotchbond Multipurpose; CF= Clearfil SE Bond; and 1, 2 or 3 = drops of primer. 
Paulo, SP, Brazil). To simulate aging of the adhesive interface, specimens were submitted to a 200.000 mechanical load at $86 \mathrm{~N}$ and 2 cycles/second thermal cycles $\left(5 \pm 1^{\circ} \mathrm{C}, 37 \pm 1^{\circ} \mathrm{C}\right.$ and $55 \pm 1^{\circ} \mathrm{C}$ with a dwell time of $30 \mathrm{~s}$ in each bath, with an interval of 15 s) generated by a thermomechanical device ER-37000 (ERIOS, São Paulo, SP, Brazil). Load was applied perpendicularly to the center of the restoration.

\section{Analysis of marginal adaptation}

After composite polishing, impressions of the teeth were formed with a low viscosity vinyl polysiloxane material (Express XT, 3M ESPE, Sumaré, SP, Brazil), and a first set of epoxy resin replicas (Epoxicure Resin, Buehler, Lake Bluff, IL, USA) was produced for SEM (LEO 435 VP, LEO Electron Microscopy Ltd, Cambridge, UK) evaluation. Following completion of the thermomechanical cycles, new impressions of the teeth were made and another set of replicas was constructed. The replicas were mounted on aluminum stubs, sputter coated with gold and evaluated using SEM at 200X magnification.

The marginal integrity between the resin composite and enamel was evaluated by examining the walls. For example, if one wall presented gaps, the restoration was assessed as having a $25 \%$ gap frequency. Marginal quality was classified according to the criteria "continuous margin" or "gap/ irregularity"11.

\section{Microtensile Bond Strength ( $\mu$ TBs)}

After storage in distilled water at $37^{\circ} \mathrm{C}$ for $24 \mathrm{~h}$, specimens were prepared for the $\mu$ TBs test using a diamond saw (Isomet 1000, Buehler Ltd, Lake Bluff, IL, USA) at 300 rpm. To obtain five $0.7 \mathrm{~mm}$ slabs, specimens were serially sectioned in the buccallingual direction, parallel to the occlusal surface. Each slab was further sectioned into three $0.7 \times 0.7 \mathrm{~mm}$ buccal dentin-composite beams.

These were individually attached to the flat grips of a microtensile tester with cyanoacrylate glue (Super Bond gel, Loctite, Henkel, São Paulo, SP, Brazil) and tested under tension force in a Universal Testing Machine (EZ Test L, Shimadzu, São Paulo, SP, Brazil) with $\pm 500 \mathrm{kgf}$ load cell at a crosshead speed of $0.5 \mathrm{~mm} / \mathrm{min}$ until failure. The cross-sectional area at the site of fracture was measured with a digital caliper (Mitutoyo Corporation, Tokyo, Japan), and bond strengths are reported in MegaPascal (MPa). The normality and homoscedasticity of the data had been analyzed previously (Shapiro-Wilk and Levene's Test, respectively). The effects of the \# of drops of primer $(1,2$ or 3 ) and adhesive system type (SBMP or CF) were analyzed via two-way ANOVA and Tukey's test using SAS Estat 9.3. Statistical significance was preset at $a=0.05$.

The fracture mode of each sample was evaluated using SEM at 90X and 450X magnification and classified as adhesive, mixed, or cohesive in dentin or resin.

\section{Nanoleakage Analysis}

Eight beams from each group were immersed in a solution of ammoniacal silver nitrate for $24 \mathrm{~h}$, washed in distilled water, immersed in light developer for $8 \mathrm{~h}$, and embedded in polystyrene resin ${ }^{12}$. Embedded samples were polished with 600-,1200-, 2000-grit SiC sandpaper and diamond paste (3-, 1-, and 0.25- $\mu \mathrm{m}$ granulations). 
Samples were demineralized and deproteinized with $85 \%$ phosphoric acid and $10 \%$ sodium hypochlorite, respectively.

Samples were dehydrated in serial ethanol solutions (25\%, 50\%, 75\%, $90 \%$, and $100 \%$ for 10 min in each concentration), and dehydration was maintained by silica until the samples were ready to be coated (with a Bal-Tec Sputter Coater SCD 050, Balzers, Liechtenstein). Samples were visualized using SEM (LEO 435 VP, LEO Electron Microscopy Ltd, Cambridge, UK) operated at $20 \mathrm{kV}$ under high vacuum power, yielding backscattered electron images.

\section{RESULTS}

\section{Microtensile bond strength test}

Analysis showed statistical significance for the factors "drops" ( $\rho=0.0057)$ and "adhesive" $(\rho=0.0015)$. However the interaction between the factors ("drops" $x$ "adhesive") was not significant $(\rho=0.3680)$. The results of Tukey's test are presented in Table 3 and 4 .

Table 3 illustrates that the highest bond strength results were obtained when one drop of primer was used. This group was significantly different from the two or three drop groups, which were not different from each other.

The three-step etch-and-rinse adhesive system demonstrated greater $\mu$ TBs than the two-step self-etch adhesive, a difference that was statistically significant, as shown in Table 4.

\section{Fracture pattern}

The most frequently observed failure mode was mixed failure in all experimental groups (figure 1). Representative SEM micrographs of treatment groups are shown in figure 2.

\section{Nanoleakage results}

In the three-step etch-and-rinse adhesive system, it was observed that infiltration increased when two or three drops of primer were used (figure 3). In the two-step

Table 3. Means and standard deviation of bond strength (MPa) for \# of drops of primer.

\begin{tabular}{llc}
\hline \# of drops of primer & Means (SD) & Tukey \\
\hline 1 & $22.05(8.86)$ & a \\
\hline 3 & $15.39(6.53)$ & b \\
\hline 2 & $12.98(6.51)$ & b \\
\hline
\end{tabular}

Different letters signify statistically significant differences (at the level of 5\%) between groups using Tukey's test.

Table 4. Means and standard deviations of bond strength (MPa) for adhesive systems.

\begin{tabular}{llc}
\hline Adhesive & Means (SD) & Tukey \\
\hline Three-step etch-and-rinse & $19.78(5.83)$ & a \\
\hline Two-step self-etch & $12.23(8.29)$ & b \\
\hline Different letters signify statistically significant differences (at the level of 5\%) between groups using Tukey's test.
\end{tabular}




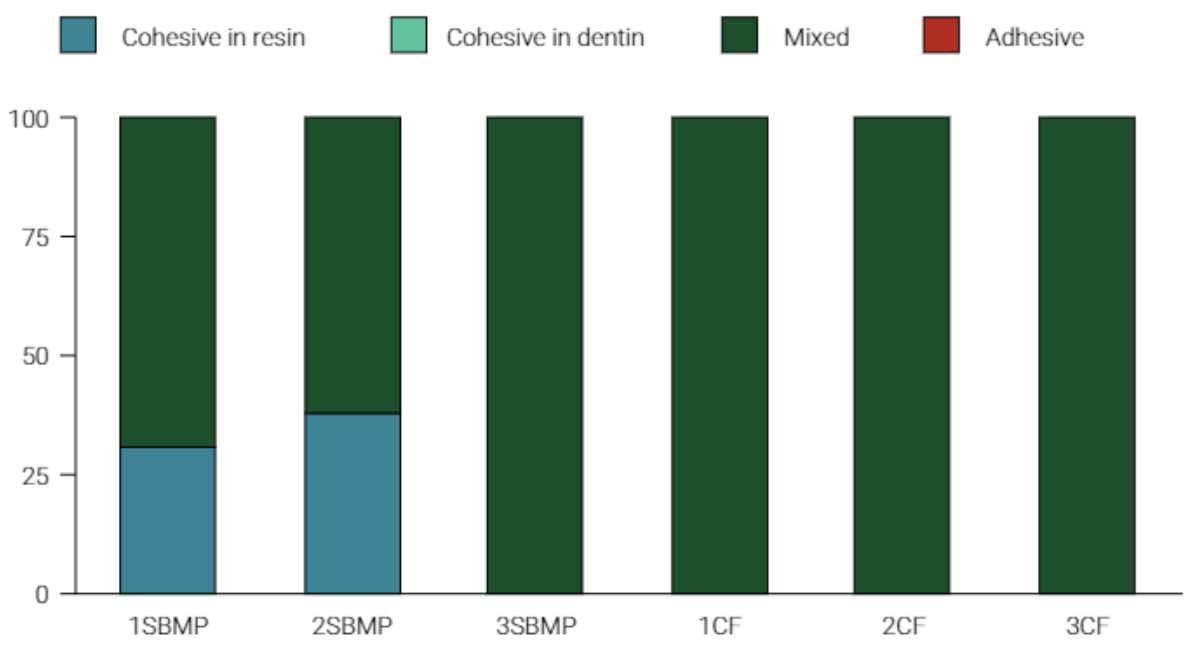

Figure 1. Percentage of failure mode for each treatment group.

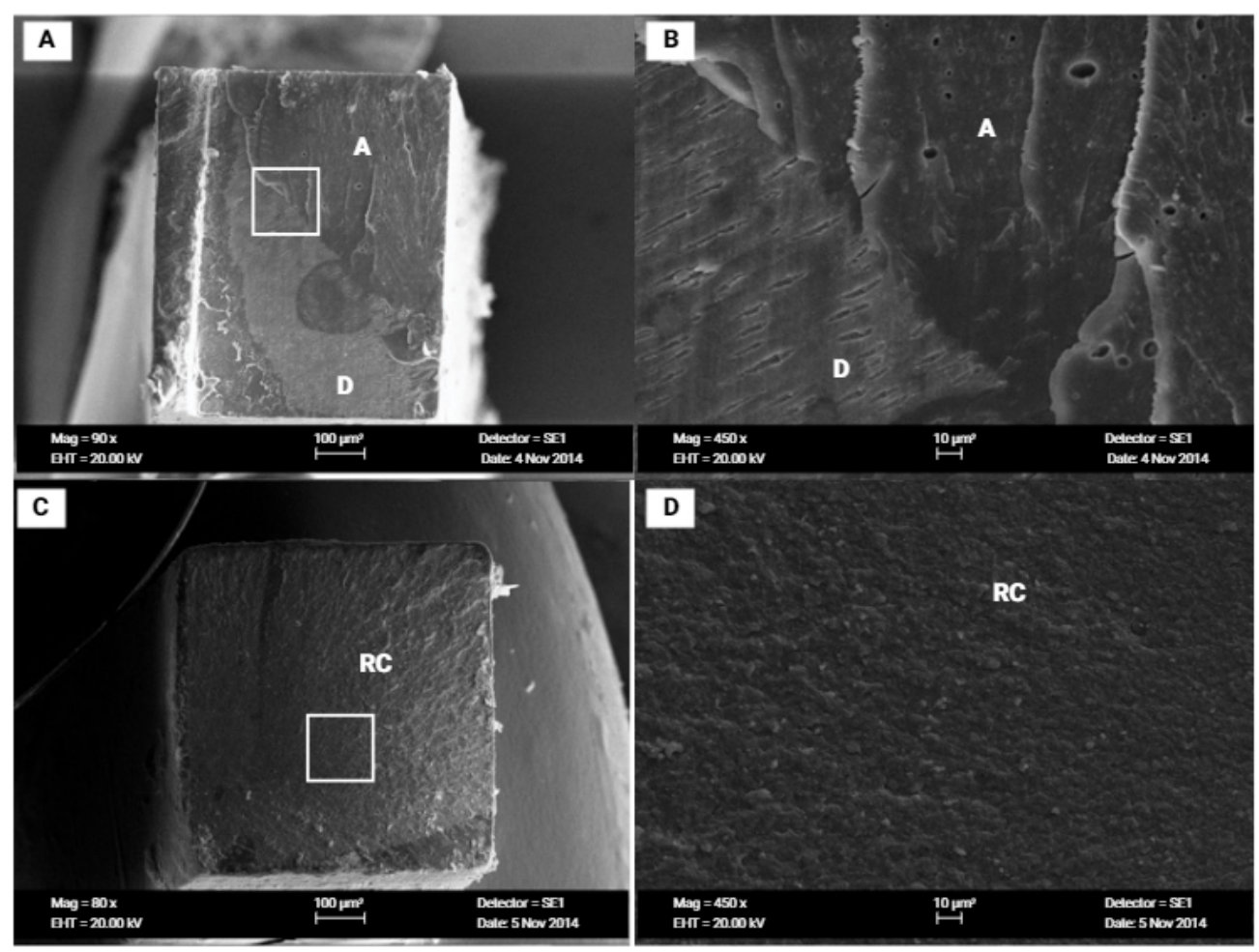

Figure 2. Representative scanning electron micrographs (SEM) of the dentin side. $R C=$ composite resin; $A=$ adhesive; $\mathrm{D}=$ dentin A low-power magnification (90x) of the $2 \mathrm{CF}$ group demonstrates a mixed failure. B Further magnification (450X) of the area defined by the rectangle in a. C low-power magnification (90x) of the 1SBMP group demonstrates cohesive failure. D Increased magnification (450X) of the area defined by the rectangle in $\mathrm{b}$.

self-etch adhesive system, there was little infiltration when one drop is used and greater infiltration and the presence of water trees when two drops were used. It was not possible to obtain images for the 3 CF group because the specimens fractured during processing (figure 4). 


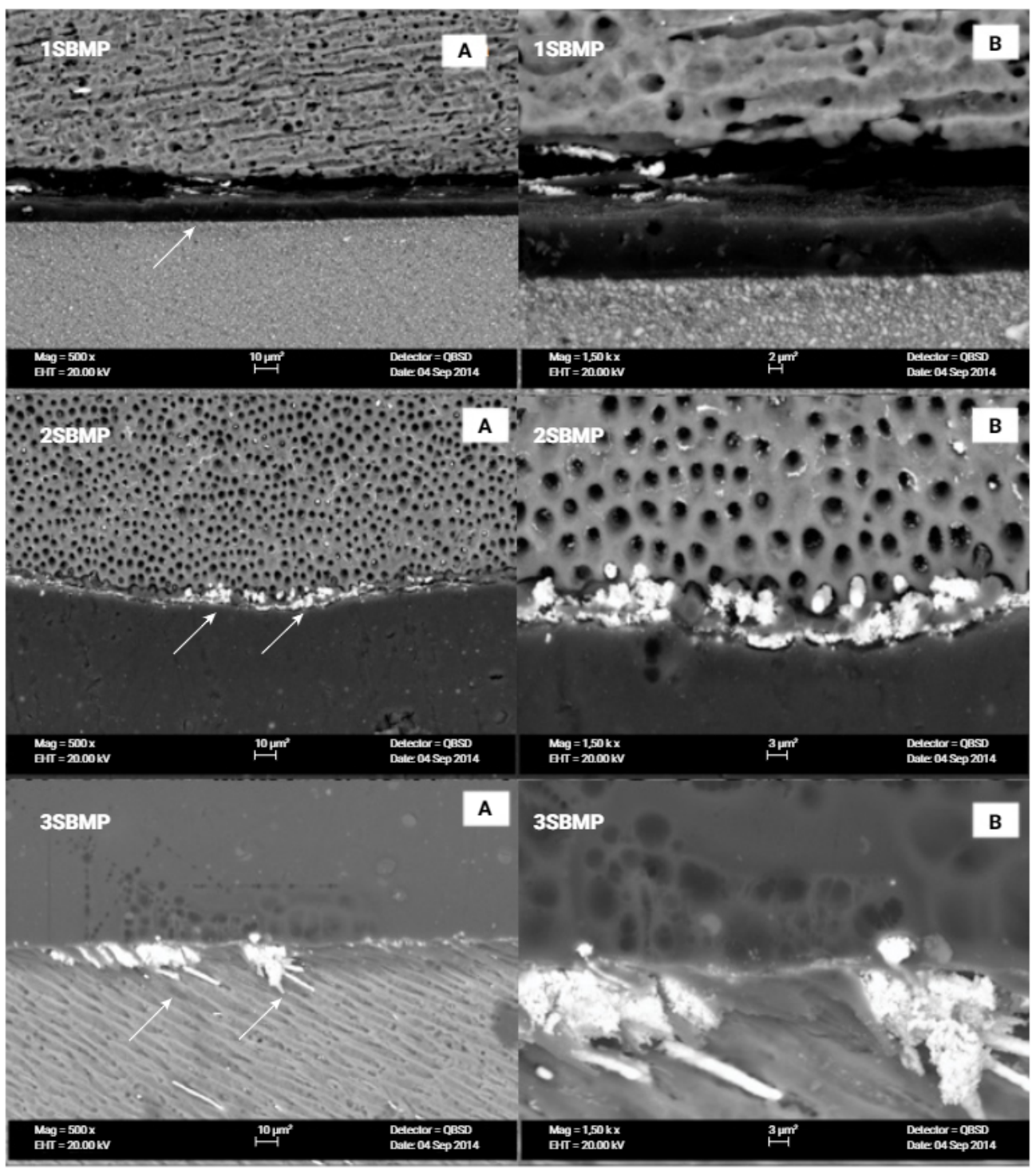

Figure 3. Representative scanning electron micrographs (SEM) show nanoleakage for the groups with the SBMP adhesive. The arrows show little infiltration of silver nitrate in the 1SBMP group, whereas, as indicated by the arrows, there was a moderate infiltration of silver nitrate in the 2SBMP and 3 SBMP groups. A) Lower magnification (500X) B) Higher magnification (1500X).

Marginal adaptation analysis

An analysis of marginal adaptation is presented in Table 5. Increased gap formation is observed following thermomechanical aging for all groups. However, there are greater gaps following aging in the groups receiving more primer. Figure 5 illustrates a representative example of gaps/ irregularity (A) versus a perfect marginal seal (B).

\section{DISCUSSION}

The critical factor for the clinical success of adhesive restorations is the quality of bonding to the dental substrate. The presence of gaps is considered the first resto- 


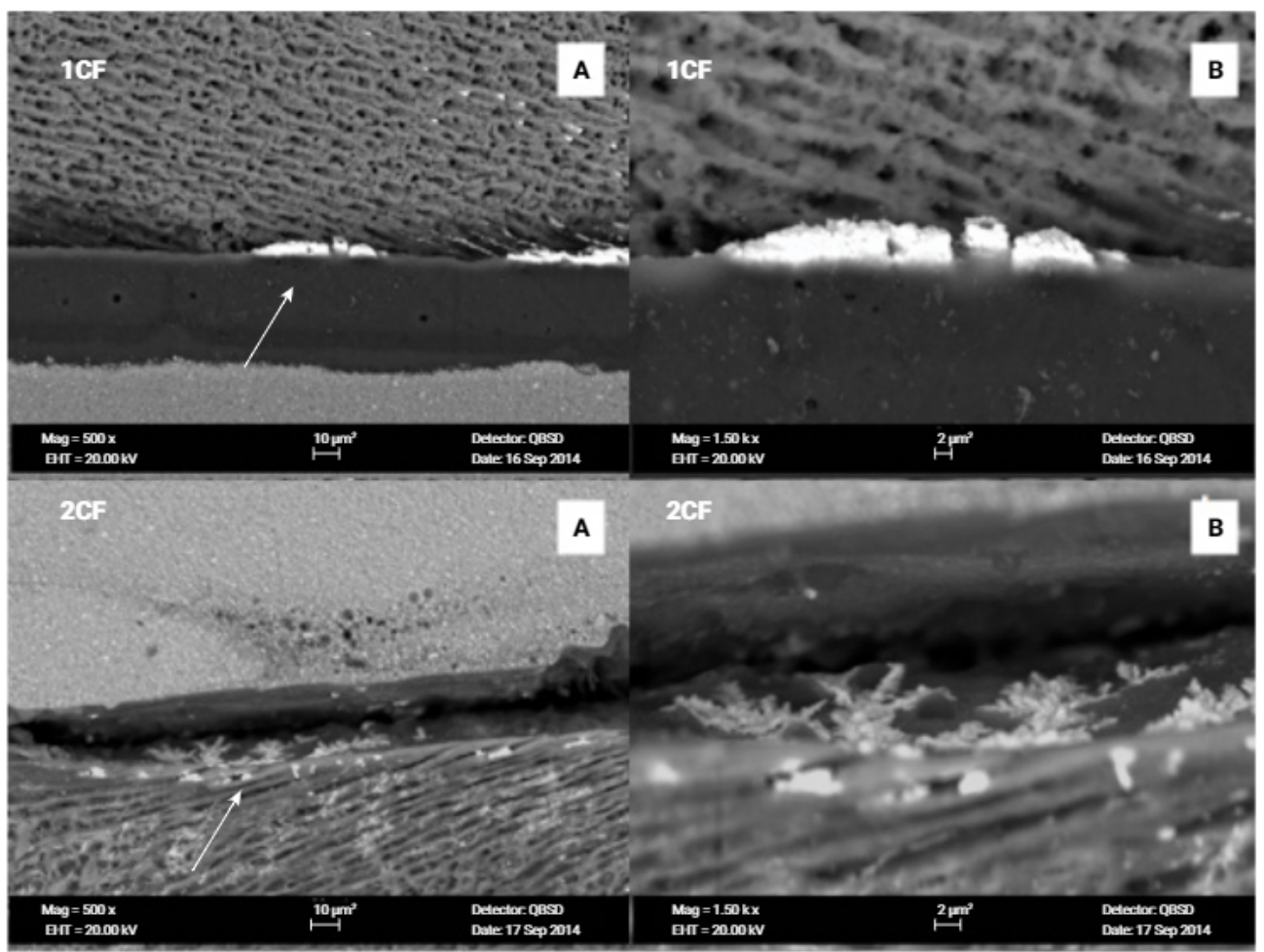

Figure 4. Representative scanning electron micrographs (SEM) show nanoleakage for the CF adhesive group. 1CF - The arrow indicates silver nitrate infiltration in the hybrid layer. 2CF - The arrow shows the presence of a water tree. A) Lower magnification (500X) B) Higher magnification (1500X)

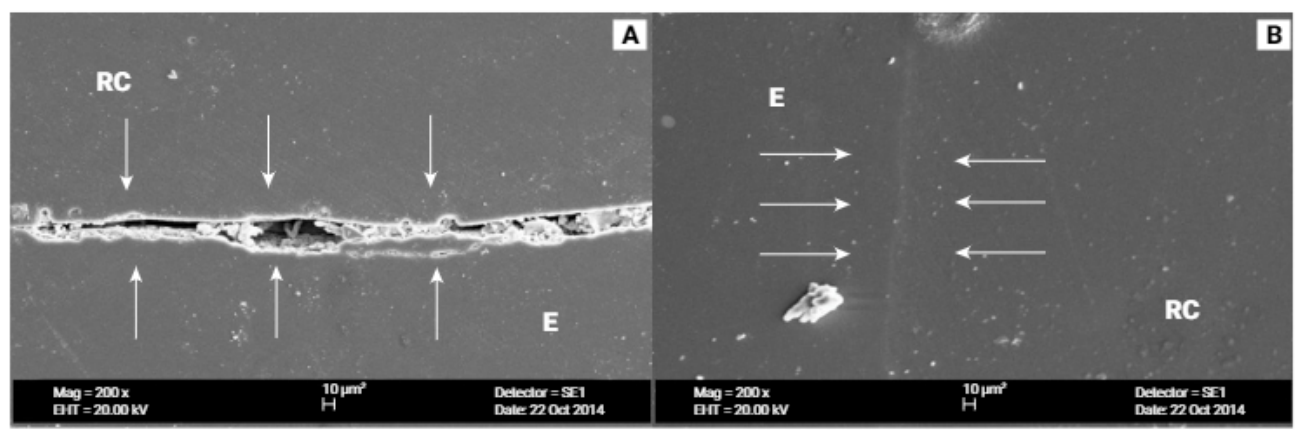

Figure 5. A - The white arrows indicate the interfacial gap formed between the composite resin and enamel. $\mathrm{B}$ - The white arrows indicate a continuous marginal between the enamel and composite. $\mathrm{RC}=\mathrm{Composite}$ Resin and $\mathrm{E}=$ enamel.

ration failure, which can lead to the infiltration of the various substances interacting with the hybrid layer ${ }^{13}$. In addition, the presence of excess water as well as incomplete monomer infiltration and polymerization results in the formation of a porous site at the bonded interface, reducing the bond strength ${ }^{14}$.

In this study, three-step etch-and-rinse showed higher bond strength values than two-step self-etch, thus rejecting the first hypothesis. The total etching technique 
Table 5. Results of gap formation/ irregularity analysis (\%) of enamel margins before and after thermomechanical aging.

\begin{tabular}{lccc}
\hline GROUPS & BEFORE AGING & AFTER AGING & $\%$ OF GAP INCREASING \\
\hline 1 SBMP & $15.6 \%$ & $40.62 \%$ & $25.00 \%$ \\
\hline 2 SBMP & $15.62 \%$ & $40.62 \%$ & $25.00 \%$ \\
\hline 3 SBMP & $15.62 \%$ & $46.87 \%$ & $31.25 \%$ \\
\hline 1 CF & $3.12 \%$ & $28.12 \%$ & $25.00 \%$ \\
\hline 2 CF & $21.87 \%$ & $46.87 \%$ & $25.00 \%$ \\
\hline 3 CF & $18.75 \%$ & $59.37 \%$ & $40.62 \%$ \\
\hline
\end{tabular}

SBMP = Scotchbond Multipurpose; CF= Clearfil SE Bond; and 1, 2 or 3 = \# of drops of primer.

promotes a demineralization area ranging from 5 to 10 micrometers ${ }^{15}$, versus that of self-etching, which has an area ranging from only 1 to 3 micrometers ${ }^{16}$. The greater area is likely because the total etching technique uses phosphoric acid with an extremely low $\mathrm{pH}(\mathrm{pH}=0.6)$, making it a more effective demineralization system than self-etching, which employs an acidic monomer with a higher $\mathrm{pH}$ (approximately 2$)^{8}$. Therefore, three-step etch-and-rinse provides a thick and more elastic hybrid layer than two-step self-etch, potentially improving bond strength ${ }^{17}$.

The self etching technique works through the association of its components: a primer, composed by acidic monomers, and a hydrophilic part, composed of HEMA and solvent ${ }^{18}$. HEMA's affinity for water allows for greater water absorption and consequently, hydrolytic degradation over time ${ }^{19}$, corroborating the results of this study that two-step self-etch presents a lower bond strength than the three-step etch-and-rinse.

This study showed that increasing the number of drops of primer decreased bond strength. The same trend was also observed following thermomechanical aging, thus supporting the second hypothesis. Incorporation of the HEMA monomer into the primer was likely responsible because HEMA as a hydrophilic monomer has the ability to absorb water, resulting in a flexible and porous polymer, similar to a gel. Water evaporates relatively rapidly from the water/HEMA mixture, leaving a greater concentration of HEMA, which reduces the water vapor pressure, thus hindering further evaporation ${ }^{20}$. The excess of water is trapped in the collagen network at the bonding interface, thus compromising the bond strength. This could promote separation of the hydrophobic and hydrophilic phases of the monomeric components, leading to incomplete sealing of dentinal tubules, reducing the conversion of the monomers, and plasticizing the polymer matrix ${ }^{2,3}$. With the increased application of primer, the amount of HEMA in the dental substrate also increases, leading to higher water absorption, thus explaining the bond strength results and nanoleakage observations. This study showed that the proper application of primer is a clinical step that cannot be neglected because when applied in excess, it can damage the bond.

The third hypothesis was supported because, as was observed via SEM for both adhesive systems, the increase in the amount of primer was proportional to the increase of infiltrate. When one drop was used, there was a small penetration of silver nitrate ions at the adhesive interface. The presence of these ions was increased to moderate 
upon addition of two or three drops, and a water tree was observed in the 2CF group. It was not possible to analyze the 3CF group using SEM because the larger amount of primer favored the accumulation of water in the hybrid layer, resulting in premature fracture of the samples when subjected to SEM vacuum.

The fourth hypothesis was also validated as all groups exhibited a greater number of gaps following thermomechanical aging. Thermomechanical cycling simulates aging because it combines thermal and mechanical cycling. The first consists of repetitive cycles alternating high and low temperatures ${ }^{9}$. This induces stress and degradation in the tooth/adhesive system interface due to differences in the thermal- linear expansion coefficient ${ }^{10}$ because rapid temperature change can promote a volumetric change affecting the adhesive stability, forming linear fracture. These gaps allow for fluid passage, contributing to nanoleakage ${ }^{21}$. In addition, it can promote the loss of filler particles, thus favoring a reduction in bond strength. The mechanical cycling component is enacted by exerting a weak stress, via repeated, subcatastrophic mechanical loading to cause initial spontaneous failure. It produces tension in the composite resin that transmits to the adhesive interface. Over time, the weak, repeated stress causes gaps between the substrate and the dental restorative material ${ }^{9}$.

Three-step etch-and-rinse showed higher $\mu$ TBs than the two-step self-etch. Furthermore, the three-step etch-and-rinse adhesive system demonstrated approximately $40 \%$ of cohesive failures in the resin and a lower infiltration of water, indicating better adhesion at the adhesive interface and less nanoleakage, than the two-step self-etch. Although thermomechanical cycling, which simulates aging of the interface, altered the performance of both adhesives, the three-step etch-and-rinse was less affected.

In conclusion, the excess primer negatively affects the mechanical properties and quality of the hybrid layer of class I type restorations when subjected to thermomechanical aging.

\section{ACKNOWLEDGMENT}

The study was supported by Coordenação de Aperfeiçoamento de Pessoal de Nível Superior-Brasil (CAPES) and the authors would like to express their gratitude to Dr. Elliot Watanabe Kitajima, from the Nucleus of Research Support NAP/MEPA/USP-ESALQ, for the SEM technical and equipment support.

\section{REFERENCES}

1. Bacelar-Sá R, Giannini M, Ambrosano GMB, Bedran-Russo AK. Dentin sealing and bond strength evaluation of Hema- free and multi mode adhesive to biomodified dentin. Braz. Dent. J. 2017;28(6):731-7. doi: 1590/0103-6440201701522.

2. Marsiglio AA, Almeida JCF, Hilgert LA, DÁlpino PHP, Garcia FCP. Bonding to dentin as a function of air-stream temperatures for solvent evaporation. Braz Oral Res. 2012 May-Jun;26;(3):282-7.

3. Rodrigues SB, Collares FM, Leitune VCB, Schneider LFJ, Ogliari FA, Petzhold CL, et al. Influence of hydroxyethyl acrylamide addition to dental adhesive resin. Dent Mater. 2015;31:1579-86. doi: 10.1016/j.dental.2015.10.005. 
4. Araújo -Neto VG, Nobre CFA, De Paula DM, Souza LC, Silva JC, Moreira MM et al. Glyceroldimethacrylate as alternative hydroplilic monomer for HEMA replacement in simplified adhesives. J Mech Behav Biomed Mater. 2018;82:95-101. doi: 10.1016/j.jmbbm.2018.03.022.

5. Munchow EA, Valente LL, Bossardi M, Priebe TC, Zanchi CH, Piva E. Influence of surface moisture condition on the bond strength to dentin of etch-and-rinse adhesive systems. Braz J Oral Sci. 2014;13(3):182-6. doi: 10.1590/1677-3225v13n3a04.

6. Pashley DH, Tay FR, Carvalho RM, Rueggeberg FA, Agee KA, Carrilho M, et al. From dry bonding to water-wet bonding to ethanol-wet bonding. A review of the interactions between dentin matrix and solvated resins using a macromodel of the hybrid layer. Am J Dent. 2007 Feb;20(1):7-20.

7. Cadenaro M, Breschi L, Rueggeberg FA, Suchko M, Grodin E, Agee K, et al. Effects of residual ethanol on the rate and degree of conversion of five experimental resins. Dent Mater. 2009;25(5):621-8. doi: 10.1016/j.dental.2008.11.005.

8. De Munck J, Van Landuyt K, Peumans M, Poitevin A, Lambrechts P, Braem M, et al. A critical review of the durability of adhesion to tooth tissue: methods and results. J Dent Res. 2005;84:118-32. doi: $10.1177 / 154405910508400204$.

9. Deng D, Yang H, Guo J, Chen X, Zhang W, Huang C. Effects of different artificial ageing methods on the degradation of adhesive-dentine interfaces. J Dent. 2014;42:1577-85. doi: 10.1016/j.jdent.2014.09.010.

10. Soares GP, Ambrosano GMB, Lima DANL, Marchi GM, Correr-Sobrinho L, Lovadino JR, et al. Effect of light polymerization time, mode, and thermal and mechanical load cycling on microleakage in resin composite restorations. Lasers Med Sci. 2014;29:545-50. doi: 10.1007/s10103-012-1244-7.

11. Garcia- Godoy R, Krämer, Feilzer AJ, Frankenberger R. Long-term degradation of enamel and dentin bonds: 6-year results in vitro vs. in vivo. Dent Mater. 2010;26:1113-8. doi: 10.1016/j.dental.2010.07.012.

12. Tay FR, Pashley DH, Suh BI, Carvalho RM, Itthagarun A. Single-step adhesives are permeable membranes. J Dent. 2002;30:371-382. doi: 10.1016/S0300-5712(02)00064-7.

13. Matos AB, Trevelin LT, Silva BTF, Francisconi-dos- Rios LF, Siriani LK, Cardoso MV. Bonding efficiency and durability: current possibilities. Braz Oral Res. 2017;31(suppl):e57. doi: 10.1590/1807-3107BOR-2017.vol31.0057.

14. Hass V, Dobrovolski M, Zander Grande C, Martins GC, Gordillo LAA, Rodrigues Accorinte Mde $L$, et.al. Correlation between degree of conversion, resin-dentin bond strength and nanoleakage of simplified etch-and-rinse adhesives. Dent Mater 2013;29(9):921-28. https://doi.org/10.1016/j.dental.2013.05.001.

15. Van Meerbeek B, Yoshihara K, Yoshida Y, Mine A, De Munck J, Van Landuyt KL. State of the art of self-etch adhesives. Dent Mater. 2011;27(1):17-28. doi: 10.1016/j.dental.2010.10.023.

16. Watanabe I, Nakabayashi N, Pashley DH. Bonding to ground dentin by a phenyl-P self-etching primer. J Dent Res. 1994 Jun;73(6):1212-20.

17. Inoue S, Vargas MA, Abe Y, Yoshida Y, Lambrechts P, Vanherle G, et al. Microtensile bond strength of eleven contemporary adhesives to dentin. J Adhes Dent. 2001 Fall;3(3):237-45.

18. Van Landuyt KL, De Munck J, Snauwaert J, Coutinho E, Poitevin A, Yoshida Y, et al. Monomer-solvent phase separation in one-step self-etch adhesives. J Dent Res. 2005;84(2):183-8. doi: $10.1177 / 154405910508400214$.

19. Giannini M, Makishi P, Ayres APA, Vermelho PM, Fronza BM, Nikaido T et al. Adhesive/Dentin Interface: Self-etch adhesive systems: A literature review. Braz Dent J. 2015;26(1):3-10.

doi: 10.1590/0103-6440201302442. 
20. Ikeda T, De Munck J, Shirai K, Hikita K, Inoue S, Sano H, et al. Effect of evaporation of primer components on ultimate tensile strengths of primer- adhesive mixture. Dent Mater. 2005;21:1051-8. doi:10.1016/j.dental.2005.03.010.

21. Yang H, Guo J, Guo J, Chen H, Somar M, Yue J, et al. Nanoleakage evaluation at adhesivedentin interfaces by different observation methods. Dent Mater J. 2015;34(5):654-62. doi:10.4012/dmj.2015-051. 